\title{
SARTURILS
}

\section{Simplifying Progress}

\section{MD8 Airscan ${ }^{\circledR}$ и MD8 AirPort ${ }^{\circledR}$}

Отбор проб воздуха активным методом для обнаружения вирусов, бактерий, дрожжей и плесени

Мониторинг воздуха в лабораториях, чистых комнатахи классифицируемых помещениях с целью обнаружения микроорганизмов в окружающей среде - повседневная задача в области фармацевтической | биотехнологической промышленности согласно текущим требованиям GMP (cGMP) Как правило, сбор данныхи анализ полученных результатов позволяет уже на раннем этапе обнаружить отклонения и предотвратить возникновение потенциальныхпроблем, вызванных превышением допустимого уровня микроорганизмов в воздухе

russia@sartorius.com

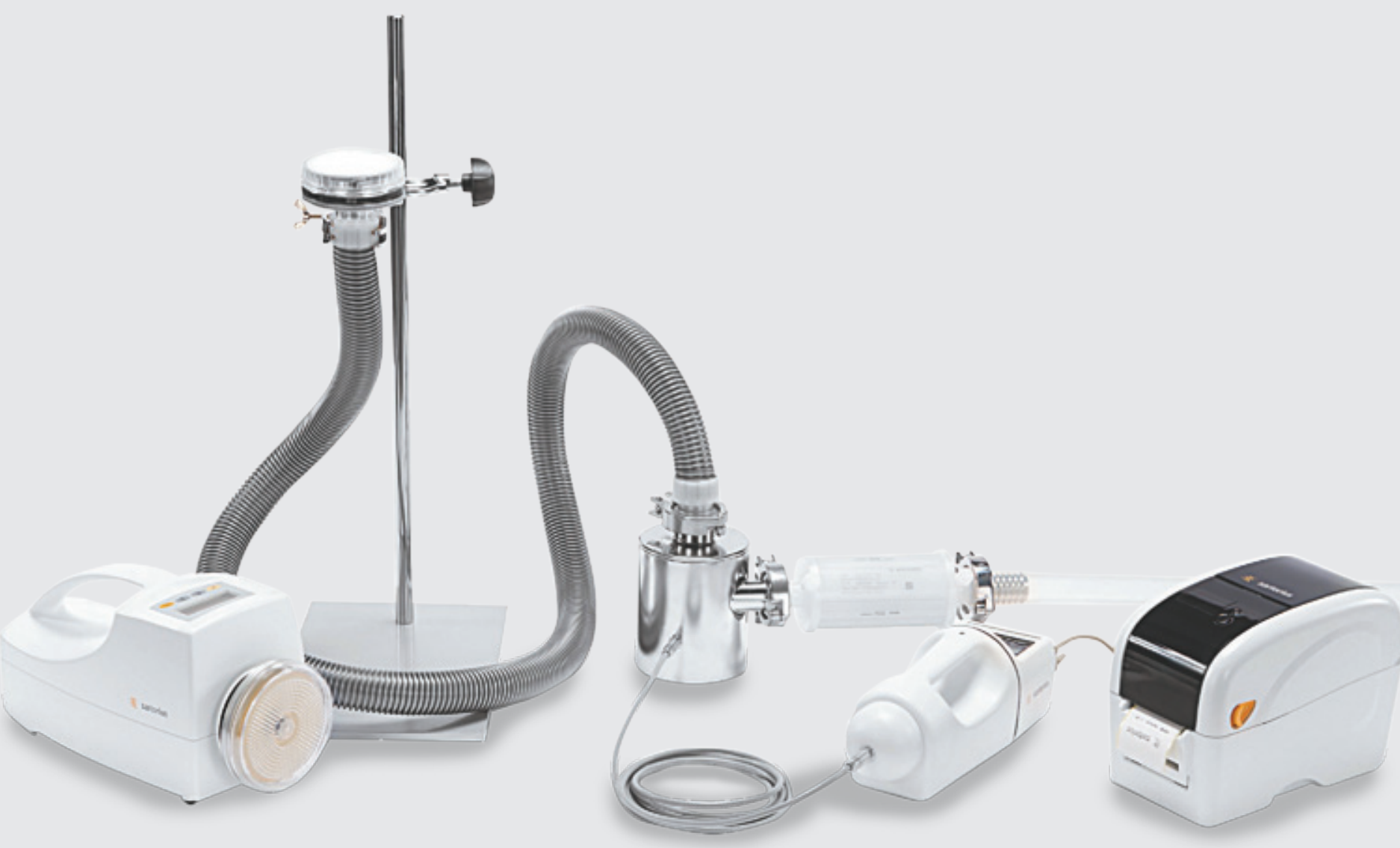




\title{
ПЕРСПЕКТИВНЫЕ МЕТОДЫ ОТБОРА ПРОБ ВИРУСНЫХ ЧАСТИЦ: ВОДОРАСТВОРИМЫЕ ЖЕЛАТИНОВЫЕ ФИЛЬТРЫ SARTORIUS
}

\begin{abstract}
Капранова М.А., ООО "Сарториус РуС", marina.kapranova@sartorius.com
Выделение респираторных вирусов из воздуха - один из наиболее важных и в то же время сложных вопросов санитарной микробиологии. Вместе с тем определение вирусной загрязненности закрытых помещений, в первую очередь больничных палат, необходимо для санитарно-вирусологического контроля воздушной среды, так как наличие патогенных микроорганизмов представляет эпидемическую опасность распространения инфекций дыхательных путей. Актуальность этой проблемы стала особенно очевидной в последние несколько месяцев на фоне разыгравшейся во всем мире вспышки коронавирусной инфекции. Одними из первых стран, осознавших необходимость микробиологических исследований воздуха, стали Китай и Япония. В 2014 году ученые Японии провели ряд исследований по обнаружению и контролю распространения вируса гриппа А, и результатом этих исследований стал обязательный мониторинг воздуха в общественных местах, в аэропортах, больницах [1]. Законодательная база Российской Федерации не регламентирует контроль содержания вирусов и вирусных частиц в воздухе ни в общественных местах, ни в специализированных комнатах для работы с микроорганизмами, ни в производственных помещениях.

Главная сложность внедрения в практику мониторинга воздуха на вирусы заключается в нахождении способа отбора пробы, при котором сохраняется жизнеспособность вирусов и вирусных частиц, с учетом низкой концентрации инфекционного агента.
\end{abstract}

Наиболее часто для активного отбора проб воздуха применяют две группы методов, использующие различные физические принципы. Работа импинджеров и импакторов основана на импакции, т.е. инерционном ударе, в результате которого взвешенные в воздухе частицы осаждаются на поверхности собирающего устройства внутри прибора, как правило, содержащего питательную среду. Другая группа методов основана на фильтрации воздуха. Возможности данного метода при работе с бактериальными аэрозолями значительно выросли с момента изобретения водорастворимых желатиновых фильтров. Сегодня такие фильтры в промышленных масштабах выпускает компания Sartorius Stedim Biotech, расположенная в городе Геттингене в Германии. Благодаря запатентованному способу изготовления желатиновых фильтров с использованием осмозащитных веществ количество собираемых на них жизнеспособных микроорганизмов удваивается по сравнению с желатиновыми фильтрами без добавок [2]. Кроме того, такие фильтры демонстрируют высокую степень механической стабильности, что позволяет увеличивать проходящий через них воздушный поток как минимум в два раза и сокращать время отбора пробы. После отбора пробы желатиновые мембранные фильтры, содержащие микроорганизмы, либо инкубируют в питательной среде, либо хранят в стерильном растворе, таком как пептонный бульон или изотонический солевой раствор. При инкубации в питательной среде желатиновый фильтр растворяется, и организмы растут непосредственно на агаре.

Обзор доступных на 2019 год методов отбора проб и обнаружения вирусов в окружающем воздухе приведен в работе [3].

Несмотря на то что эффективность желатиновых фильтров для исследования бактерий была продемонстрирована в ряде исследовательских работ [4-6], данные об их применении для вирусов оставались весьма скудными и ограничивались лишь несколькими работами [7-9].

До недавних пор фильтры ограниченно применялись при обнаружении и отборе вирусов из аэрозолей, поскольку использование фильтров считалось эффективным только в случае стабильных и резистентных вирусов, если вообще было возможным.

Чтобы последовательно разобраться с предлагаемым методом мониторинга, в статье представлены исследования, проведенные в 1991 году Хельмутом Яшхофом (Helmut Jaschhof), одним из авторов патента на желатиновые фильтры компании Sartorius [10].

Работа проводилась с использованием экспериментально полученных аэрозолей колифагов Т1 и Т3, а также 
вирусов гриппа (штамм A|PR|8|34 (H1N1)), и убедительно продемонстрировала, что применение желатиновых фильтров типа 12602 производства Sartorius Stedim Biotech обеспечивает стабильную эффективность отбора указанных вирусных частиц даже при высоких скоростях входящего потока (до 1,6 м/с) и длительном времени отбора (до 15 мин).

Успешное испытание эффективности данного метода на практике в условиях сезонного пика острых респираторных заболеваний (ОР3) в начале 1990 г. (3-5-я неделя) оказалось возможным благодаря высокой механической стабильности желатинового фильтра и устойчивости вируса гриппа. Исследование основывалось на результатах испытаний с использованием экспериментально полученных аэрозолей вирусов и бактериофагов.

Пробы воздуха отбирали на протяжении 3 дней в помещении приемного покоя детской поликлиники г. Грайфсвальда. Далее водорастворимые фильтры с отобранным материалом помещали в среду для культивирования вирусов. Параллельно проводились эксперименты по культивированию вирусных частиц из назального секрета пациентов детского возраста, поступивших в приемный покой с недавно выявленными ОРЗ.

\section{ЭКСПЕРИМЕНТАЛЬНАЯ ЧАСТЬ}

Материалы и методы. Исследованное помещение: приемный покой детской поликлиники г. Грайфсвальда (объем

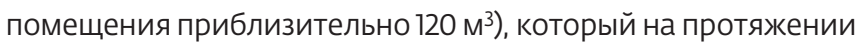
2 часов посетили не более 57 детей в сопровождении родителей. Температура: $+25^{\circ} \mathrm{C}$, относительная влажность $60 \%$.

Материалы исследования. Назальный секрет пациентов детского возраста с недавно выявленными ОРЗ. Желатиновый фильтр производства Sartorius Stedim Biotech (тип 12602-050). Фильтрование воздуха производилось в течение 3 дней с пропусканием 1,8 м³ воздуха через каждый желатиновый фильтр каждые 15 минут при скорости потока воздуха 120 л/мин.

После отбора пробы фильтр упаковывали в полиэтиленовый пакет с 5 мл изотонического буферного раствора для культивации клеток (рН 7,4), содержащего 0,5\% дрожжевой экстракт (Difco), пенициллин G (400 ЕД/мл) и стрептомицин (400 мкг/мл). Все образцы выдерживались в течение 4 часов (для промежуточного хранения использовалась холодильная камера).

\section{Вирусологические анализы}

Назальный секрет. К пробам добавили раствор Хенкса (по 3 мл на каждую пробу) и центрифугировали в течение 30 мин на скорости 3000 об./мин с добавлением 10 мкл раствора антибиотика на 1 мл супернатанта, после чего проводили инкубацию в течение 1 ч при комнатной температуре. Амниотическую жидкость куриных яиц, подвергавшихся

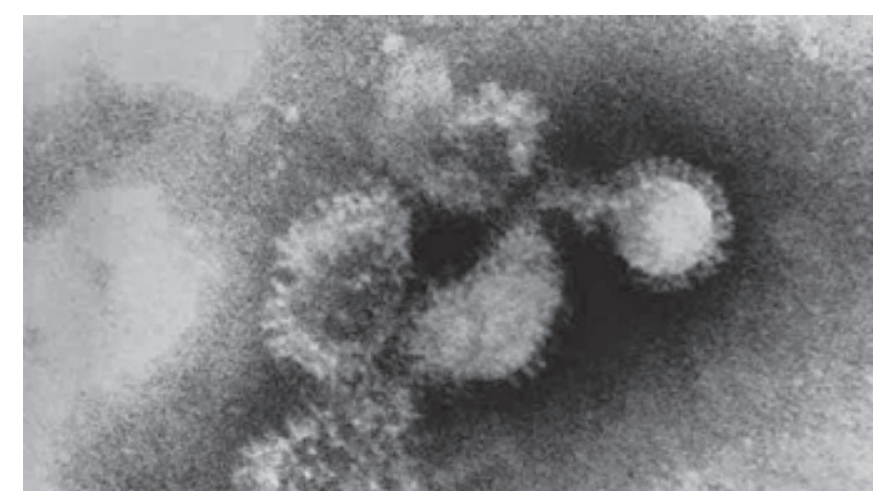

Рис.1. Сканирующая электронная микрофотография вируса грunna A|PR/8/34 (HONI), выделенного из культуры эмбриона куриного яйща (время культивирования - 11 дней). Вирусные частицы выделяли методом центрифугирования в градиенте плотности сахарозы

инкубации на протяжении 10 дней, высевали вместе с данными пробами и инкубировали в течение 3 дней при температуре $+33^{\circ} \mathrm{C}$. Были приготовлены 3 пересеянных культуры для слепого исследования; вирусы выявляли с помощью реакции торможения гемагглютинации (РТГА).

Пробы воздуха. Материал фильтров растворяли с добавлением буфера при нагревании на водяной бане в течение 5 мин и при температуре $+37^{\circ} \mathrm{C}$. Как описывалось выше, раствор антибиотика добавляли к суспензии, которую использовали для инокуляции инкубированных куриных яиц. Затем в среде культивировали клетки человеческого амниона линии FL и клетки асцитной карциномы. Для обнаружения вирусов использовали стандартные методы: РТГА, тест на наличие цитопатического действия (ЦПд) и реакцию на торможение гемадсорбции (РТГад).

Вирус гриппа, полученный из назальных выделений, типировали и идентифицировали путем перекрестного титрования, используя реакцию пассивной гемагглютинации с иммунными сыворотками крови кролика, содержащими антитела к вирусу гриппа A|Greifswald|1|89 (H1N1) и A|Greifswald|1|90 (H3N2) и антигены вируса гриппа A|Sichuan|2|87 (H3N2) и вируса гриппа A|Greifswald|2|88 (H3N2).

Вирусные РНК и паттерны белков вирусов определяли методом электрофореза в полиакриламидном геле.

\section{ОБСУЖДЕНИЕ РЕЗУЛЬТАТОВ}

В день исследования из находившихся в помещении детей в возрасте от 8 лет 75\% имели респираторные инфекции, острые катаральные симптомы: кашель, чихание, насморк проявлялись не более чем у 40\% пациентов. Из отобранных экспериментальных материалов были выделены три типа вирусов из назального секрета 


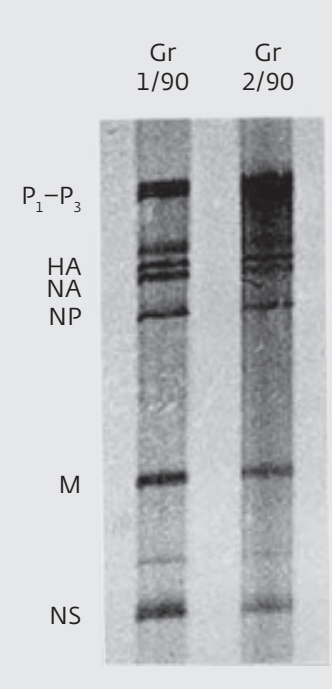

Рис.2. Разделение РНК вируса гpunna A/Greifswald|I|90 (H3N2), выделенного из проб пациентов, и вируса гриппа A/Greifswald|2/90, собранного и выделенного из воздуха, методом электрофореза в полиакриламидном геле

и вирус гриппа А из пробы воздуха. Данные вирусы были успешно культивированы в среде инкубированных куриных яиц с эмбрионами во время третьего пассажа с целью пересева (вирус гриппа A|Greifswald|2|90 [H3N2]) (рис.1).

Анализ методом РТГА показал, что антигены выделенных вирусов и антигены вариантов A|Greifswald|2|88 и A|Sichuan|2|87 были в целом аналогичными и не отли-

\section{ЛИТЕРАТУРА}

1. Hatagishi E., Okamoto M., Ohmiya S., Yano H., Hori T. et al. Establishment and Clinical Applications of a Portable System for Capturing Influenza, Viruses Released through Coughing // PLoS ONE. 2014. V. 9. N 8. e103560. doi:10.1371/journal.pone.0103560.

2. Herbig H., Jaschhof H., Vinh R.T. Gelatin membrane filters and method for producing the same // US6406906B1. 2000.

3. Pan M., Lednicky J.A. , Wu C.-Y. Collection, particle sizing and detection of airborne viruses // Journal of Applied Microbiology. 2019. V. 127. P. 1597-1611. doi.org/10.1111/jam.14278.

4. Burton N.C., Grinshpun S.A., Reponen T. Physical Collection Efficiency of Filter Materials for Bacteria and Viruses // The Annals of Occupational Hygiene. 2007. V. 51. P. 143-151. https:// doi.org/10.1093/annhyg/mel073.

5. Lewandowski R., Kozłowska K., Szpakowska M., Trafny E.A. Evaluation of applicability of the Sartorius Airport MD8 sampler for detection of Bacillus endospores in indoor air // Environ Monit Assess. 2013.n. V. 185. N 4. P. 3517-3526. doi: 10.1007/ s10661-012-2807-6.

6. Fabian P., McDevitt J.J., Houseman E.A., Molton D.K. Airborne influenza virus detection with four aerosol samplers using molecular and infectivity assays: considerations for a чались от штамма, культивированного из носовых выделений пациента, который находился в помещении во время отбора проб воздуха с помощью фильтров (вирус гриппа A|Greifswald|1|90 [H3N2]).

Скорости миграции белков выделенных вирусов (НА, NP, NS и M) и все полосы вирусных РНК, полученные методом электрофореза в полиакриламидном геле, имели высокую степень соответствия (рис.2). Попытки выделения других вирусов из проб воздуха с помощью клеточных культур оказались неудачными.

Взятие проб во время преэпидемической фазы распространения ОРЗ подтверждает эффективность метода сбора с помощью фильтров для обнаружения аэрозольных частиц вируса гриппа.

Обнаружение вируса гриппа А в воздухе приемного покоя детской поликлиники в период незначительного увеличения сезонной заболеваемости ОРЗ в регионе хорошо согласуется с данными по исследованию экспериментально созданных статических аэрозолей колифагов и вируса гриппа А [11] и подтверждает практическую пригодность желатиновых фильтров для отбора из воздуха частиц респираторных вирусов.

$$
* * * *
$$

Учитывая относительное сокращение трудозатрат при использовании несложного метода фильтрования, применение желатиновых мембранных фильтров служит перспективным средством для анализа возникновения, стабильности и распространения инфекционных вирусных аэрозолей, например, в области генной инженерии.

new infectious virus aerosol sampler // Indoor Air. 2009. V. 19. P. 433-441. doi.org/10.1111/j.1600-0668.2009.00609.x.

7. Zuo Zh., Kuehn T.H., Verma H., Mor S.K., Goyal S.M., Appert J., Raynor P.C., Ge S., Pui D.Y. Assotiation of Airborne Virus Infectivity and Survivability with its Carrier Particle Size // Aerosol Science and Technology. 2013. V. 47. P. 373-382. doi.org /10.1080/02786826.2012.754841.

8. Zhao Y., Aarnink A.J.A., Wang W., Fabri T., Groot Koerkamp P.W. and de Jong M.C. Airborne virus sampling - efficiencies of samplers and their detection limits for infectious bursal disease virus (IBDV) // Ann Agric Environ Med 2014. V. 21. P. 464-471.

9. Tseng C.C. Li C.S. Collection efficiencies of aerosol samplers for virus-containing aerosols // J Aerosol Sci. 2005. V. 36. P. 593-607.

10. Jaschhof H., Finke E.J., Herrmann B. Detecting Airborne Influenza Virus A // Sartorius Stedim Biotech, 2009. Application Note No.: SM-4018-e09066.

11. Jaschhof H. Collection of Viruses and Phages with the Gelatin Membrane Filter Method // Sartorius Stedim Biotech, Application Note SLF4028-e04014. 


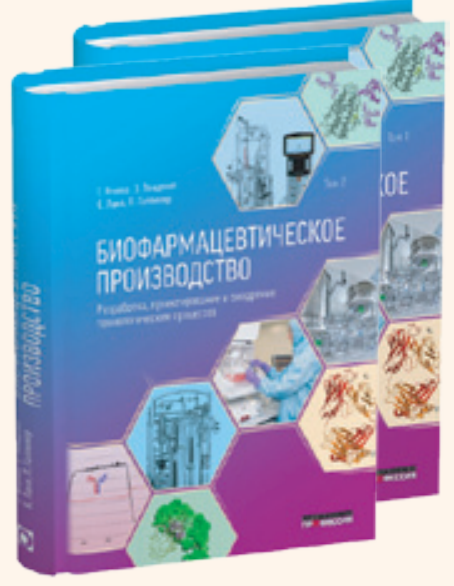

\title{
БИОФАРМАЦЕВТИЧЕСКОЕ ПРОИЗВОДСТВО. Разработка, проектирование и внедрение технологических процессов
}

\author{
Г. Ягшиш, Э. Линдског, К. Лаки, П. Галлихер
}

Перевод с англ. (2018, Biopharmaceutical Processing. Development, Design, and Implementation of Manufacturing Processes)

Под ред. Ишмухаметова А.А., Пятигорской Н.В. 2020 г., 2 тома, ок. 1500 с., цв.ил., табл., тв. пер., 210×270 мм

Цена -9500 p.

В уникальном издании рассматривается весь спектр биотехнологий от создания линии клеток до получения лекарственной субстанции. Описанные в нем методы и стратегии представляют собой сведения, необходимые для всех исследователей, инженеров-технологов и специалистов, занятых в области производства биофармацевтических препаратов и вакцин.

Целостность биопроцесса в конечном итоге определяет качество биотерапевтического препарата, и в настоящей книге подробно рассматриваются все стадии производства, включая все технологии, связанные с очисткой целевого продукта и процессом культивирования. Особое внимание уделено обширным экономическим аспектам с рекомендациями по уменьшению затрат и повышению эффективности. Приведены многочисленные данные, расчеты и руководства, что позволяет использовать издание в качестве незаменимого инструмента для исследователей и управленческих работников биофармацевтической отрасли. В специальных главах рассмотрены аналитические методы и вопросы регулирования.

Российскими авторами, сотрудниками регуляторных и ведущих научных учреждений (Федеральной службы по надзору в сфере здравоохранения (Росздравнадзор), Федерального научного центра исследований и разработки иммунобиологических препаратов им. М.П. Чумакова РАН, кафедры промышленной фармации Первого Московского государственного медицинского университета имени И.М. Сеченова) добавлены главы, касающиеся аспектов обращения биопрепаратов в Российской Федерации и странах ЕАЭС; рассмотрены актуальные регуляторные требования к фармаконадзору и государственному контролю качества биологических препаратов, освещены принципы производства продукции на первичной культуре клеток, современные подходы к процессу лиофилизации, производство полиомиелитных вакцин, аспекты качества и безопасности биопрепаратов. Широкий круг рассматриваемых в данных главах вопросов делает издание особенно ценным для отечественных разработчиков и производителей биофармацевтических препаратов.

Издание не имеет российских аналогов и адресовано специалистам биофармацевтических производств - исследователям, биотехнологам, биоинженерам, разработчикам вакцин, биосубстанций и препаратов, руководителям и менеджерам, отвечающим за организацию, внедрение, безопасность и контроль качества, органам регулирования и надзора биофарамацевтических производств, преподавателям и студентам профильного направления.

\section{Оглавление}

1. Здравоохранение и биофармацевтическая промышленность, препараты и процессы

2. Принципы и методы upstream-процессов (культивирования)

3. Процессы, принципы и методы выделения целевого продукта

4. Процессы очистки, принципы и методы

5. Оборудование для биопроизводства

6. Проектирование промышленного процесса

7. Проектирование и эксплуатация производственной площадки

8. Аналитические методы, регуляторные нормативы, аспекты качества и безопасности

9. Финансовое управление и стоимость процесса 